\title{
12. TEMPERATURE AND TILT VARIATION MEASURED FOR 64 DAYS IN HOLE 581C 1
}

\author{
Fred K. Duennebier, Robert K. Cessaro, and David Harris, Hawaii Institute of Geophysics²
}

\begin{abstract}
The ocean sub-bottom seismometer obtained continuous temperature and tilt data in Hole 581C during a 64-day period after drilling and another temperature measurement $81 \frac{1}{2}$ months later. These data are used to obtain a heat-flow estimate through the 110-m.y.-old crust and to determine the mechanical stability of the instrument. Temperature results show rapid temperature increase during the first week after drilling, and then a secondary trend of increasing temperature extending over several months. It does not appear possible to model these data with simple theory, and extrapolation of the temperature increase obtained during the first 6 days yields an equilibrium temperature $0.6^{\circ}$ higher than that obtained from the total data set. We interpret these data to mean that the drilling water invaded and cooled the region around the hole.

The tilt sensors in the instrument are not sensitive enough to record tectonic tilt variations. However, even with their low sensitivity, they show that the platform had not reached equilibrium by the end of the 64-day recording period.
\end{abstract}

\section{INTRODUCTION}

The ocean sub-bottom seismometer (OSS) contains calibrated tilt and temperature sensors with outputs that are digitally recorded once every $32 \mathrm{~min}$. in the recorder package. OSS IV was emplaced within $4 \mathrm{~m}$ of the bottom of Hole $581 \mathrm{C}$ (5467 $\mathrm{m}$ water depth, $357 \mathrm{~m}$ sediment, $21 \mathrm{~m}$ basalt, $378 \mathrm{~m}$ total penetration). From 11 September to 16 November 1982, a continuous record of the tilt and temperature changes was obtained by the OSS system. In addition, the tilt and temperature were again measured on 26 May 1984, during the reload of the recorder package. Although tilt and temperature measurements were not first priority data in this experiment, measurements were taken for minimal added cost yielding unique data sets for further analysis.

\section{BACKGROUND}

OSS IV (on Leg 88) was the fourth attempt at emplacement of a permanent borehole seismometer. Previous successful experiments were run on Legs 65 and 67. OSS I data in Hole $482 \mathrm{C}$ (Leg 65) indicated temperatures near $150^{\circ} \mathrm{C}$ after 42 days in the hole (Duennebier et al., 1983). This temperature was about $50^{\circ} \mathrm{C}$ hotter than extrapolated from heat-flow measurements taken in the sediments during drilling, leading us to conclude that the hole formed a "hot well" allowing overpressured water from below to flow up the hole.

Temperature and tilt data from OSS II (Leg 67) in the Guatemala Trench are discussed in Carter et al. (1981). Resolution of the tilt and temperature data for this experiment was poor, and, although there was little temperature variation, tilt changes too large to be tectonic in origin were recorded. As this tool was locked in sediments, large tilt changes could be expected. The OSS III experiment failed because of hardware problems.

\footnotetext{
${ }^{1}$ Duennebier, F. K., Stephen, R., Gettrust, W. T., et al., Init. Repts. DSDP, 88: Washington (U.S. Govt. Printing Office)

Address: Hawaii Institute of Geophysics, University of Hawaii, 2525 Correa Road, Honolulu, HI 96822.
}

The OSS IV tilt and temperature sensors are recorded with much better resolution than was available in the earlier instruments, largely because of subtraction of the $\mathrm{dc}$ level prior to digitization (the dc level is recorded separately), and presetting of the temperature sensor zero output value near the expected bottom hole temperature, $15^{\circ} \mathrm{C}$. The tilt sensors (Fredricks Model 7660 bubble tiltmeters) were calibrated to $\pm 1 \mathrm{mrad}$ absolute on the HIG shaker table facility (Duennebier et al., 1984). The temperature sensor was calibrated in the tool to $\pm 0.01^{\circ} \mathrm{C}$ using a constant temperature bath and calibrated thermometers. The temperature sensor is an integrated circuit device (Analog Devices AD590) mounted against the pressure case in the tool. The resolution of the tiltmeters is $\mathbf{8}$ digital units per microradian, and the resolution of the temperature sensor is 11 digital units per millidegree (at highest gain). Although earth tides are still unresolved in the tilt data by about an order of magnitude, a more sensitive tilt sensor would require active leveling of the sensors in the tool.

\section{RESULTS}

\section{Tilt Data}

During installation of OSS IV in Hole $581 \mathrm{C}$ on 11 September 1982, it was necessary to lock and unlock the tool several times before it settled into an attitude where both horizontal geophones were sensitive. The reason for including tilt sensors in the package was to supply engineering data on tool attitude. After locking the tool in position, it tilted about $1 \mathrm{mrad}\left(0.1^{\circ}\right)$ to the northeast during the first few days, usually in steps, and then drifted toward the southwest at a steadily decreasing rate over the next 60 days (Figs. 1, 2). The recorded tilt variations are several orders of magnitude larger than any reasonable tectonic tilts and are probably caused by gradual settling of the tool in the hole. The tool is locked in basalt, however, and the long time needed to approach equilibrium was not expected. Some of the step changes in tilt shortly after emplacement correlate with high noise pulses on the geophones, probably indicating settling of 

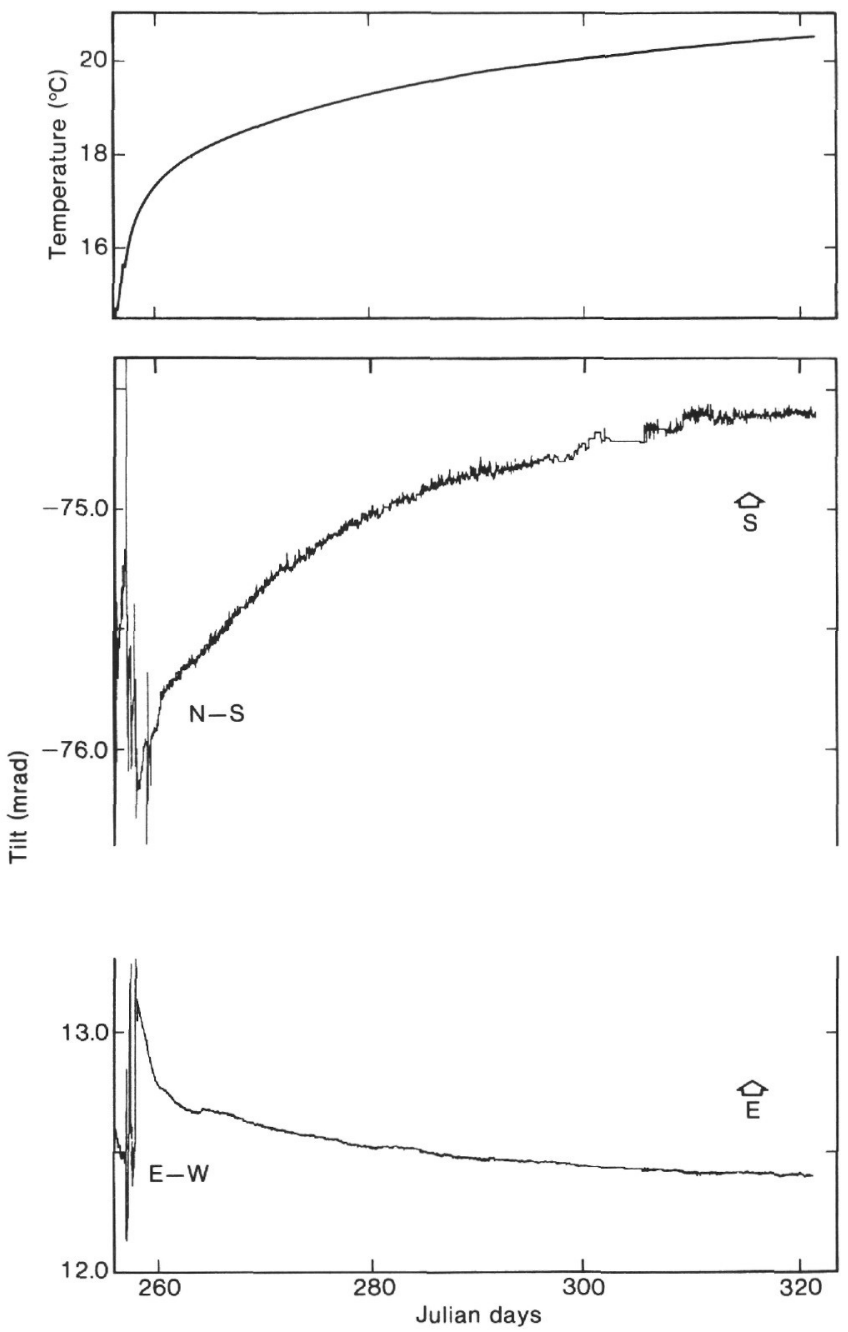

Figure 1. Variation in tilt and temperature at the bottom of Hole 581C during the 64 days of continuous measurement by the ocean subbottom seismometer.

the instrument and cable in the hole. One of the largest tilt changes occurred the day after emplacement (at about 0800 on Julian day 257); the tilt change correlates with a sharp decrease in the temperature (Fig. 2) as well as a noise pulse on the geophones. In this case, we hypothesize that a large amount of cooler sediment fell down from above, moving the tool (changing the tilt), and significantly cooling the water at the base of the hole. The resulting cooling pulse decays rapidly compared to the long-term thermal effects of drilling.

The recording system was refurbished on 25 May 1983, $81 / 2$ months after emplacement. Tilt and temperature measurements were monitored for about 1 day during servicing with minimal disturbance of the instrument in the hole. At this time, the tilts were at $2.9 \mathrm{mrad}$ (east-west) and $26.5 \mathrm{mrad}$ (north-south). These values are much closer to vertical than expected from a simple extrapolation of the recorded data, and the cause of this change is not known. Perhaps it was because of further material collapses in the hole. Variations of 0.1 to $0.5 \mathrm{mrad}$ occurred while servicing the recorder package, probably caused by disturbing the hole when tugging on the wire connecting the instrument in the hole to the ship. The magnitude 7.8 Japan earthquake of 26 May 1983 was recorded by the tilt sensors as well as the geophones (Duennebier, this volume).

\section{Temperature Data}

The temperature measurements obtained from emplacement on 11 September 1982 until 16 November 1982 are a unique data set: they are the longest continuous recording of ocean borehole temperature in existence. The temporal change in temperature should contain information on heat flow and permeability at the drill site. Although only the heat flow is estimated in this report, models to estimate other variables can certainly be constrained by these data. In addition to the continuous 64day data set, a temperature value $\left(21.42^{\circ} \mathrm{C}\right)$ was obtained 259 days after emplacement, when the system was refurbished on 26 May 1983. Another 60-day data set starting on that date is still waiting to be recovered.

Inspection of the temperature change with time (Figs. $1,2)$ shows that the hole was cooled by the drilling process, warmed rapidly during the first two weeks after drilling, and continued to warm slowly over the 64-day recording period. The hole then warmed almost $1^{\circ}$ during the 250 days between the end of recording and refurbishing the system. To model this change in temperature, an attempt was made to use the simple formulation of Lachenbruch and Brewer (1959):

$$
T=A \ln [t /(t-S)]+T_{0}
$$

where $T=$ temperature at time $t$ after the start time of the disturbance $\left({ }^{\circ} \mathrm{C}\right), \mathrm{A}=$ constant, $t=D-D_{0}$, where $D$ is the day of year and $D_{0}$ is the start day of the disturbance, $S=$ duration of disturbance in days, and $T_{0}=$ equilibrium temperature $\left({ }^{\circ} \mathrm{C}\right)$.

If this formulation is valid, then a plot of $\ln [t /(t-S)]$ versus $T$ should be linear with a slope of $A$ and intercept $T_{0}$. As shown in Figure 3, this is not the case. Using reasonable estimates for the start time and duration of the disturbance, the resulting plots are concave upward, implying that the hole took much longer to warm back up after the cooling caused by drilling than would be expected from this simple theory.

The Lachenbruch and Brewer (1959) formulation assumes a line source with no volume or heat capacity. A more complete theory (Bullard, 1947) includes the volume of the hole and the final temperature of the water in the hole at the end of the drilling disturbance. This theory assumes that the duration of the drilling is instantaneous.

The Bullard (1947) theory is given by the equation:

$$
\begin{gathered}
T(t)-T_{0}=\Delta T F(\alpha, \tau), \text { where } \\
F(\alpha, \tau)=\frac{4 \alpha}{\pi^{2}} \int_{0}^{\infty} \frac{e^{-u^{2} \tau} d u}{u\left\{\left[u J_{0}(u)-\alpha J_{1}(u)\right]^{2}+\left[u Y_{0}(u)-\alpha Y_{1}(u)\right]^{2}\right\}}
\end{gathered}
$$

where $u=$ the integration variable, $T(t)=$ the hole temperature at time $t$ (days) after drilling, $T_{0}=$ the forma- 


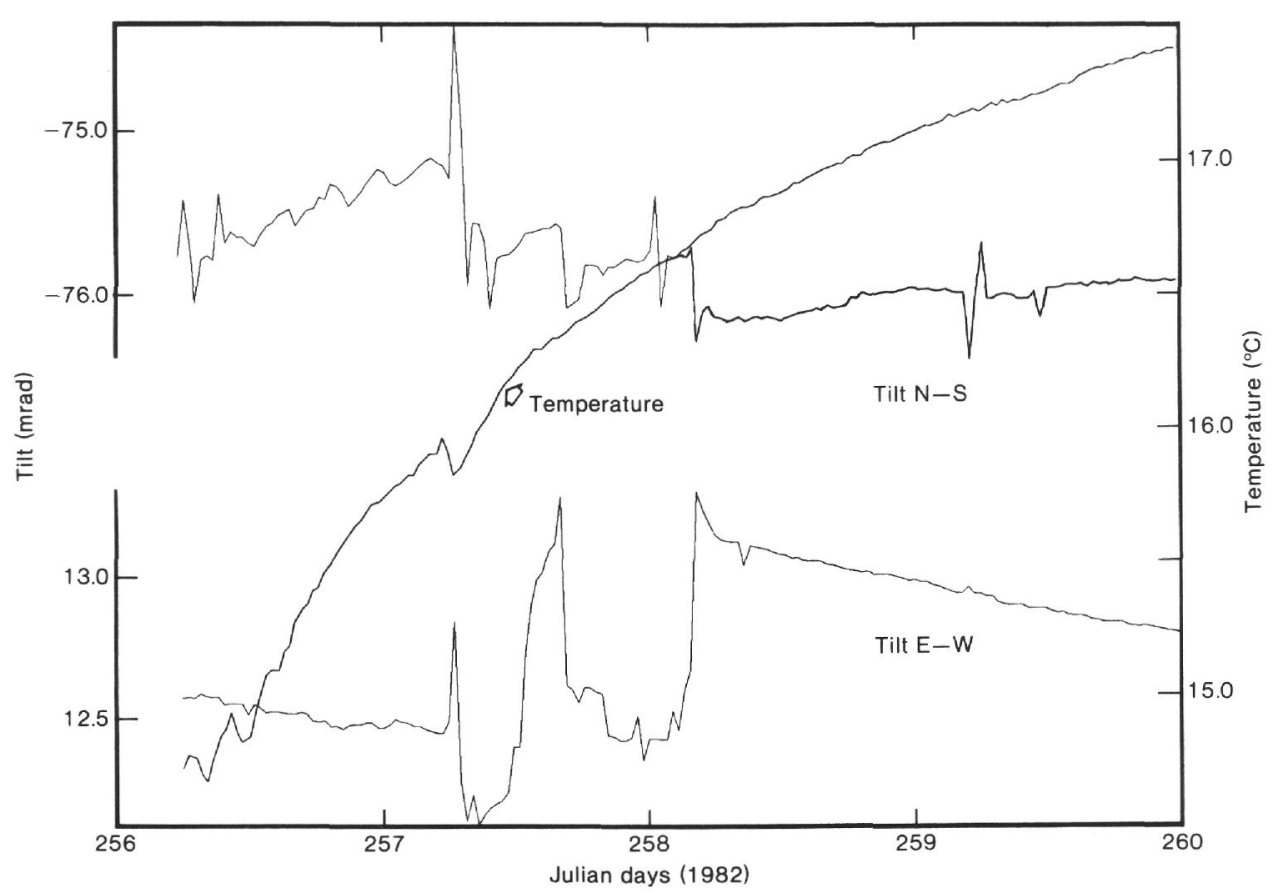

Figure 2. Tilt and temperature data for the first 4 days of measurement. The cooling event at 0800 on Julian day 257 correlates with a change in tilt and a noise pulse on the geophones, implying that it was caused by material falling down the hole.

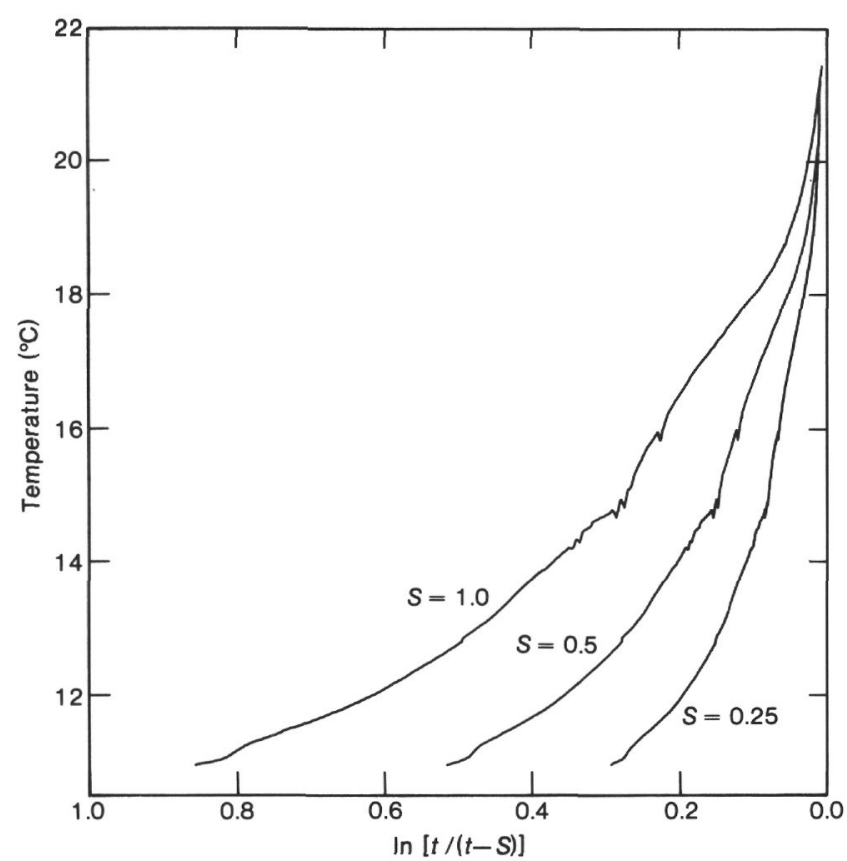

Figure 3. A comparison of observed temperature changes using three different reasonable estimates for $S$, the duration of drilling in days, $t$ is the time since the beginning of the drilling disturbance in days. Note that the curve is concave rather than linear, implying that the region around the hole was cooled by the drilling much more than predicted by simple line source theory.

tion equilibrium temperature, $\Delta T=$ the instantaneous temperature change from equilibrium caused by drilling, $\alpha=$ twice the ratio of the heat capacity of the borehole seawater to the surrounding crust, $\tau=\kappa t / a^{2}$, where $\kappa=$ the thermal diffusivity of the crust and $a=$ the ra- dius of the borehole, and $Y_{0}, Y_{1}, J_{0}$, and $J_{1}=$ Bessel functions.

In our case, we must estimate the parameters $T_{0}, \alpha$, and $\tau$ to obtain a reasonable fit to the observed data set. This formulation was used for analysis of the Leg 78B temperature data (Becker et al., 1984), and their notation is used here. If we assume that $\alpha=1.25$ (Hyndman et al. 1984), and $\kappa=0.65 \mathrm{~mm}^{2} / \mathrm{s}$, we can vary $T_{0}, \Delta T$, and $a$ to look for a reasonable fit to the data. Increasing the value of $T_{0}$ raises all temperatures by equal amounts. In our case, $\Delta T$ is negative, and making it more negative (lowering the initial temperature of the hole) decreases $T(t)$ for small values of $t$, but has little effect when $t$ is large. Increasing the radius of the hole $(a)$ increases the time constant of return to equilibrium. The initial temperature of the hole must not be less than $0^{\circ} \mathrm{C}$, as this is the minimum temperature of seawater pumped into the hole, thus $T_{0}-\Delta T \geq 0^{\circ} \mathrm{C}$. If we set the hole radius at $12.7 \mathrm{~cm}(5 \mathrm{in}$.), the fit to the data is poor, and we find that we must use a larger hole radius $(60 \mathrm{~cm})$ to obtain reasonable agreement with the data recorded during the first 6 days after drilling. Since the caliper in OSS IV measured the hole diameter as $25.4 \mathrm{~cm}$, this disagreement is real, possibly indicating that the assumption of instantaneous drilling time is not valid for times shortly after drilling is completed. An equilibrium temperature of $22.6^{\circ} \mathrm{C}$ and hole radius of $60 \mathrm{~cm}$ were used to obtain the fit to the early data, shown as the dashed curve in Figure 4. Whereas the fit is always within $0.2^{\circ} \mathrm{C}$ during the first 6 days, the fit to the remaining data (Fig. 5) using these values is poor, since the predicted temperature is higher than the observed values.

To obtain a fit to the complete temperature data set, we combine the effects of the warming of two separate 


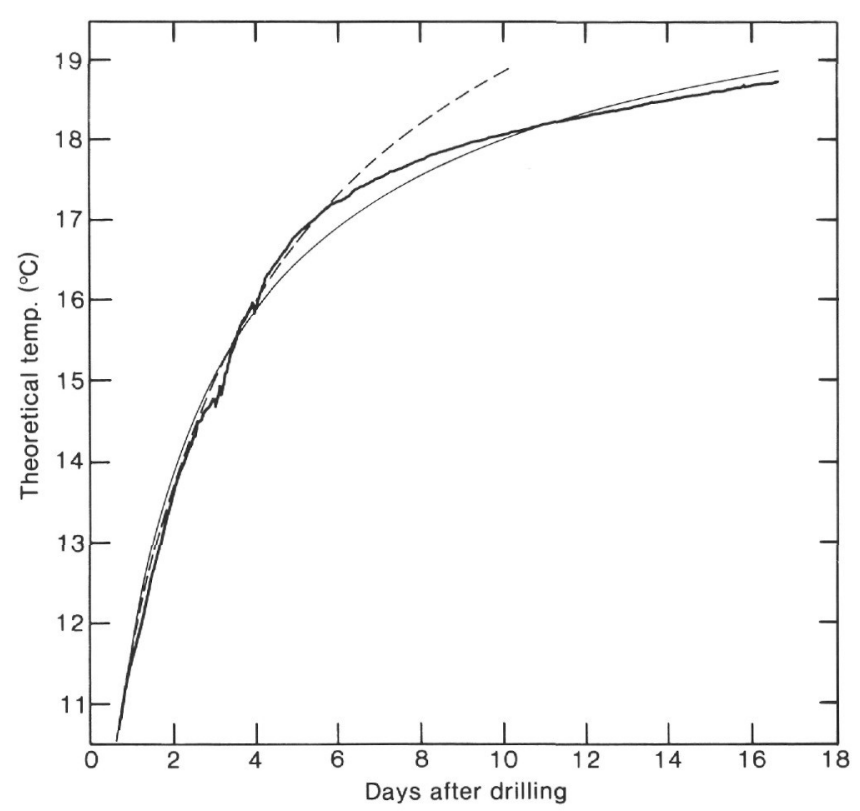

Figure 4. Bullard formula fit to the temperature data taken shortly after drilling. The data are shown by the heavy solid curve. The dashed curve was obtained using the Bullard formula with an equilibrium temperature of $22.6^{\circ} \mathrm{C}$ and a hole radius of $60 \mathrm{~cm}$. This curve fits the first 6 days of data well, but predicts higher temperatures at later times. The thin solid curve was obtained using a tworegion model explained in the text.

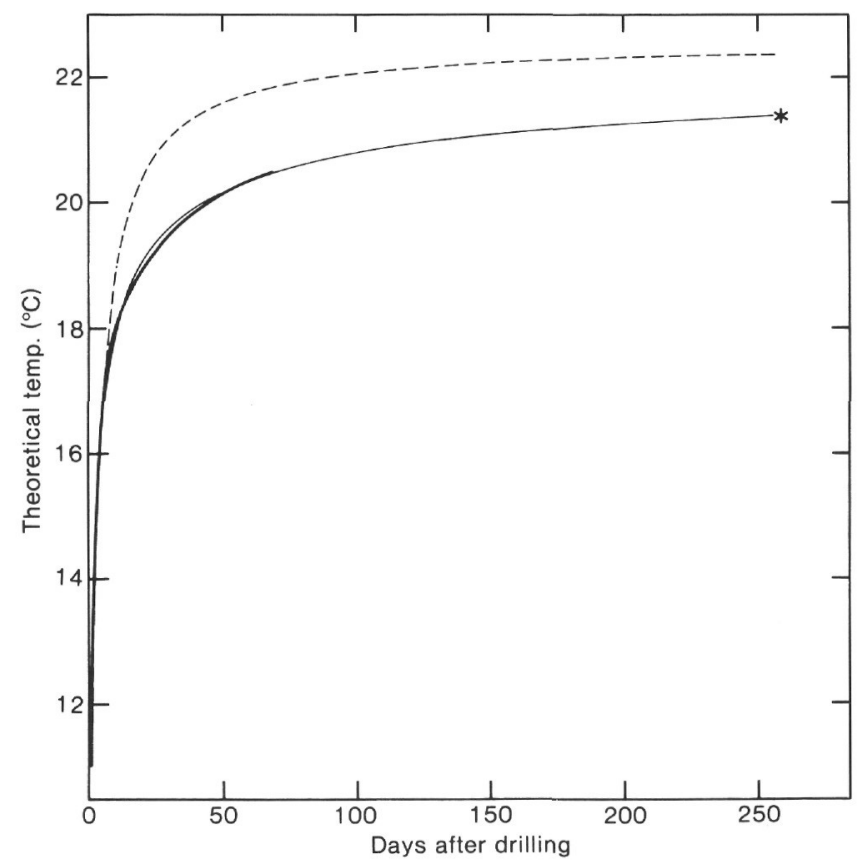

Figure 5. Bullard formula and modified Bullard formula fit to the complete temperature data set. The heavy solid line shows the continuous 64-day data set; the asterisk shows an additional data point obtained 256 days after drilling. The dashed curve was obtained using the same parameters as the dashed curve in Figure 4. The thin solid line was obtained by modeling two regions cooled by drilling rather than just the hole. The dashed predicts an equilibrium temperature about $0.6^{\circ}$ warmer than the other model. regions-one being the hole and its immediate vicinity and the second being a much larger region surrounding the hole. We hypothesize that the larger region was substantially cooled during drilling by drilling water forced into the formation. We model this effect using Bullard's formulation by combining the warming trends of the two regions as if they were independent, with the equilibrium temperature of the smaller region being the instantaneous temperature of the larger region. We make no claims on the validity of this procedure, but we expect that it supplies a first-order approximation to reality. Parameters that can be varied are the hole radius, radius of the invaded zone, equilibrium temperature of the region, initial temperature of the hole, and initial temperature of the invaded zone. The curve (thin solid line) in Figures 4 and 5 was obtained by setting the hole radius $=39.5 \mathrm{~cm}$, radius of the invaded zone $=2.4 \mathrm{~m}$, equilibrium temperature $=22.0^{\circ} \mathrm{C}$, initial temperature of the invaded zone $=18.0^{\circ} \mathrm{C}$, and initial temperature of the hole $=0^{\circ} \mathrm{C}$. These parameters (found by trial and error) provide a reasonable fit to the data, within $0.2^{\circ} \mathrm{C}$ at nearly all points of the curve. The equilibrium temperature $\left(22.0^{\circ} \mathrm{C}\right)$ is probably accurate to within a few tenths of a degree.

The theory of Jaeger $(1956,1961)$ was also suggested by a reviewer as a possible model for comparison with these data. This model uses the duration of drilling as a boundary condition, similar to the Lachenbruch and Brewer (1959) formulation discussed earlier. For our case, the tool is emplaced in the very bottom of the hole, and the duration of drilling is very short (hours), so that the Jaeger theory predicts that the hole should return to equilibrium much faster than the data show. Thus, modeling using this formulation was not attempted.

\section{Heat Flow at Site 581}

Magnetic data from the site (Hilde et al., 1976; Bleil, 1985; Grim and Gettrust, this volume) suggest that the ocean crust at Site 581 has an age of about 110 m.y. From Parsons and Sclater (1977), the predicted heat flow for $110-\mathrm{m}$.y.-old crust is about $1.2 \mathrm{cal} / \mathrm{cm}^{2} \mathrm{~s}$. This is in exact agreement with a heat-flow value taken at $43^{\circ} 53.5^{\prime} \mathrm{N}, 159^{\circ} 45^{\prime} \mathrm{E}$, very close to the OSS site during the ZETES expedition (Vacquier et al., 1966). We can obtain an estimate of the heat flow at Site 581 by assuming that the temperature at the ocean floor is $0^{\circ} \mathrm{C}$ and estimating the conductivities of the sediments and basement. Using $k_{\mathrm{b}}=4.0 \mathrm{mcal} /\left(\mathrm{s} \mathrm{cm}^{\circ} \mathrm{C}\right)$ for the thermal conductivity of the basalt (Hyndman et al., 1977), and $\kappa_{\mathrm{s}}=1.8 \mathrm{mcal} /\left(\mathrm{s} \mathrm{cm}^{\circ} \mathrm{C}\right)$ for the sediments (Vacquier et al., 1966) and Hole 581C parameters (sediment thickness of $357 \mathrm{~m}$ and basalt thickness of $21 \mathrm{~m}$ to the bottom of the hole), we can obtain the heat flow from the formula for heat transmission through two layers:

$$
H F=\frac{T_{\mathrm{e}}-T_{\mathrm{w}}}{\frac{D_{\mathrm{s}}}{\kappa_{\mathrm{s}}}+\frac{D_{\mathrm{b}}}{\kappa_{\mathrm{b}}}}
$$

where $T_{\mathrm{e}}=$ equilibrium temperature at the tool depth, $T_{\mathrm{w}}=$ bottom water temperature, $D_{\mathrm{s}}$ and $D_{\mathrm{b}}=$ thick- 
nesses of sediment and basement to the tool depth, $\kappa_{\mathrm{s}}$ and $\kappa_{\mathrm{b}}=$ conductivities of sediment and basement, and $H F=$ heat flow.

The heat flow is $1.08 \mathrm{cal} / \mathrm{cm}^{2} \mathrm{~s}$, in good agreement, but with somewhat lower than the predicted values, assuming the temperature at the ocean floor is $0^{\circ} \mathrm{C}$, and an equilibrium temperature at the tool of $22.0^{\circ} \mathrm{C}$. If only the temperature data from the first week had been available, the extrapolated equilibrium temperature of $22.6^{\circ} \mathrm{C}$ would have given a heat flow value of 1.11 .

\section{CONCLUSIONS}

Tilt and temperature data for a 259-day period including 64 days of continuous measurement, supply a unique data set for hole settling and thermal history. These data suggest that basement holes can take a very long time, possibly years, to reach equilibrium after drilling, making temperature and tilt extrapolations shortly after drilling suspect. By themselves, data of this type from permanently occupied holes are of limited value, but if arrays of such instruments could be emplaced, both vertically and in other holes, then considerable information could be obtained about the thermal conditions and state of stress in the region.

\section{ACKNOWLEDGMENTS}

This study was sponsored by the Hawaii Institute of Geophysics and the Office of Naval Research. Editorial assistance was given by Rita Pujalet and Diane Henderson. We thank David Epp and Dr. Marcus Langseth for their help in analysis of these data. Hawaii Institute of Geophysics Contribution No. 1670.

\section{REFERENCES}

Becker, K., Langseth, M. G., and Hyndman, R. D., 1984. Temperature measurements in Hole 395A, Leg 78B. In Hyndman, R. D. Salisbury, M. H., et al., Init. Repts. DSDP, 78B: Washington (U.S. Govt. Printing Office), 689-698.

Bleil, U., 1985. The magnetostratigraphy of Northwest Pacific sediments, Deep Sea Drilling Project Leg 86. In Heath, G. R., Burckle, L. H., et al., Init. Repts. DSDP, 86: Washington (U.S. Govt. Printing Office), 441-458.
Bullard, E. C., 1947. The time necessary for a borehole to attain temperature equilibrium. Monthly Notices, R. Astron. Soc., Geophys. Suppl., 5:127-130.

Carter, J. A., Hussong, D. M., and Duennebier, F. K., 1981. Downhole temperature and tilt results from three DSDP holes. EOS, Trans. Am. Geophys. Union., 62(45):1054-1055. (Abstract)

Duennebier, F. K., Blackinton, J. G., and Gieskes, J., 1983. A manmade hot spring on the ocean floor. In Lewis, B. T. R., Robinson, P., et al., Init. Repts. DSDP, 65: Washington (U.S. Govt. Printing Office), 357-359.

Duennebier, F. K., Sutton, G. H., Harris, D., and Byrne, D. A., 1984 A simple shaker table for seismometer calibration. Mar. Geophys. Res., 6:311-328.

Hilde, T. W. C., Isezaki, N., and Wageman, J. M., 1976. Mesozoic seafloor spreading in the north Pacific. In Sutton, G. H., Manghnani, M. H., and Moberly, R. (Eds.), The Geophysics of the Pacific Ocean Basin and Its Margin. Am. Geophys. Union Monogr., 19:205-226.

Hyndman, R. D., Christensen, N. I., and Drury, M. J., 1984. The physical properties of basalt core samples from Deep Sea Drilling Project Leg 78B Hole 395A. In Hyndman, R. D., Salisbury, M. H., et al., Init. Repts. DSDP, 78B: Washington (U.S. Govt. Printing Office), 801-810.

Hyndman, R. D., Von Herzen, R. P., Erickson, A. J., and Jolivet, J., 1977. Heat-flow measurements DSDP Leg 37. In Aumento, F., Melson, W. G., et al., Init. Repts. DSDP, 37: Washington (U.S. Govt. Printing Office), 347-362.

Jaeger, J. C., 1956. Numerical values for the temperature in radial heat flow. J. Math. Phys., 34:316.

1961. The effect of the drilling fluid on temperatures measured in boreholes. J. Geophys. Res., 66(2):563-569.

Lachenbruch, A. H., and Brewer, M. C., 1959. Dissipation of the temperature effect in drilling a well in Arctic Alaska. U.S. Geol. Surv. Bull., 1083-C:73-109.

Parsons, B., and Sclater, J. G., 1977. An analysis of the variation of ocean floor bathymetry and heat flow with age. J. Geophys. Res., 82:803-827.

Vacquier, V., Uyeda, S., Yasui, M., Sclater, J., Corry, C., and Watanabe, T., 1966. Studies of the thermal state of the earth. The 19th paper: Heat-flow measurements in the northwestern Pacific. Bull. Earthquake Res. Inst., 44:1519-1535.

Date of Initial Receipt: 13 August 1984 Date of Acceptance: 27 February 1986 


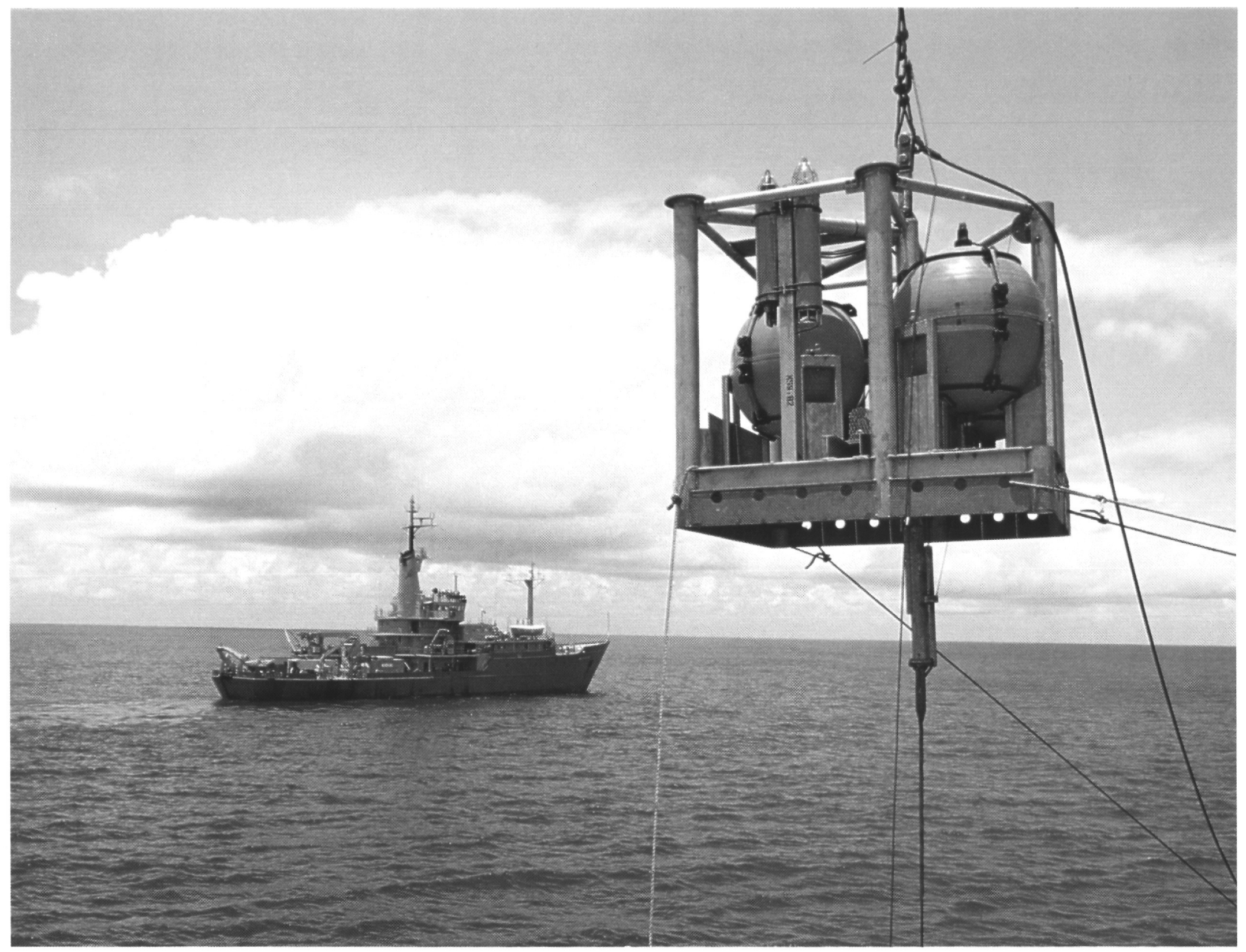

The Bottom Processing Package of DARPA's Marine Seismic System in position to be lowered into the water using the main crane of the Glomar Challenger. The Melville stands by. 